\title{
Migration of Vanadium in the Ecosystem \\ of Kuchurgan Cooling Reservoir of the Moldovan Thermal Power Plant
}

\author{
Elena I. Zubcova*a, Alexander A. Protasov ${ }^{b}$, \\ Lucia I. Biletski ${ }^{a}$, Natalia N. Zubcova ${ }^{a}$, \\ Laurentia N. Ungureanu ${ }^{a}$, Lilia N. Tihonenkova ${ }^{a}$, \\ Elena N. Philipenko and Anjelika A. Silaeva ${ }^{\mathbf{b}}$ \\ ${ }^{a}$ Institute of Zoology, Academy of Sciences of Moldova \\ 1 Academiei Str., Chisinau, MD 2028, Moldova \\ ${ }^{b}$ Institute of Hydrobiology of NAS of Ukraine \\ 12 Geroev Stalingrada Ave., Kiev, 04210, Ukraine
}

Received 21.12.2016, received in revised form 22.04.2017, accepted 19.10.2017

The article describes the results of long-term research on the dynamics of vanadium migration in water, bottom sediments, higher aquatic plants, bottom invertebrates, and fishes in the cooling reservoir of the Moldovan Thermal Power Plant. An obvious dependence of the level of vanadium in aquatic ecosystem on the quantity and composition of burnt fuel at the plant was established. In most of cases the migration of vanadium in the system "water - silts" occured from water layers to bottom sediments. But if the intensity of sulphate reduction and putrefaction processes increases and the concentration of dissolved oxygen decreases the reverse diffusion from silts to water will become possible. The level of accumulation of metals in hydrobionts is one of the most important parameters in the biomonitoring of metals in aquatic ecosystems. The concentration of vanadium in aquatic plants and animals depended on the intensity of metabolism and interspecific features, plastic and generative metabolism (at fish), but in the same time reflected the dynamics of vanadium in the environment. The values of the coefficient of vanadium biological accumulation in aquatic organisms reached up to $n \times 10^{7}$.

Keywords: vanadium, thermal power plant, cooling reservoir, monitoring, pollution, metals, hydrobionts.

Citation: Zubcova E.I., Protasov A.A., Biletski L.I., Zubcova N.N., Ungureanu L.N., Tihonenkova L.N., Philipenko E.N., Silaeva A.A. Migration of vanadium in the ecosystem of Kuchurgan cooling reservoir of the Moldovan Thermal Power Plant. J. Sib. Fed. Univ. Biol., 2017, 10(4), 446-458. DOI: 10.17516/1997-1389-0044.

(C) Siberian Federal University. All rights reserved

* Corresponding author E-mail address: elzubcov@mail.ru 


\title{
Миграция ванадия в экосистеме
}

\section{Кучурганского водоема-охладителя Молдавской ГРЭС}

\author{
Е.И. Зубкова ${ }^{a}$, А.А. Протасов \\ Л.И. Билецки ${ }^{\text {a }, ~ Н . Н . ~ З у б к о в а ~}{ }^{a}$, Л.Н. Унгурянуа, \\ Л.Н. Тихоненкова ${ }^{a}$, Е.Н. Филипенко ${ }^{a}$, А.А. Силаева ${ }^{\sigma}$ \\ ${ }^{a}$ Институт зоологии АН Молдовы \\ Молдова, МD 2028, Кичинев, ул. Академическая, 1 \\ ${ }^{6}$ Институт гидробиологии НАН Украинь \\ Украина, 04210, Киев, пр. Героев Сталинграда, 12
}

В статье отражены результаты многолетних исследований динамики миграции ванадия в воде, донных отложениях, высшей водной растительности, донных беспозвоночных и рыбах водоема-охладителя Молдавской ГРЭС. Установлена четкая зависимость уровня ванадия в водной экосистеме от количества и состава сжигаемого на станциии топлива. Миграция ванадия в системе вода - иловые отложения в большинстве случаев идет из водных слоев в донные отложения, но при интенсификации процессов сульфатредукции, гниения, при уменьшении концентрации растворенного кислорода возможна и обратная диффузия из илов в воду. Уровень накопления металлов в гидробионтах - один из важнейших показателей при биомониторинге металлов в водных экосистемах. Показано, что концентрация ванадия в водных растениях и животных определяется интенсивностью процессов метаболизма, межвидовыми особенностями, интенсивностью пластического и генеративного обмена (у рыб) и в то же время является отражением динамики ванадия в среде обитания. Коэффициент биологического накопления в водных организмах достигал величины $n \times 10^{7}$.

Ключевые слова: ванадий, теплоэлектростанциия, водоем-охладитель, мониторинг, загрязнение, металль, гидробионтыл.

\section{Введение}

В последние годы появляется все больше данных о биологической роли ванадия и особенно, о его токсичности (Asadpour et al., 2013; Proctor et al., 2002). Динамика его в окружающей среде, по данным Всемирной организации здравоохранения, вызывает особый интерес (Report WHO, 2001). Одним из основных источников загрязнения окружающей среды ванадием является сжигание твердого и жидкого топлива. В каменном угле его концентрации варьируют в пределах 14-56 мг/кг, в сырой нефти - в диапазоне 3-260 мг/кг и в остаточном жидком топливе - 0,2-160 мг/кг. В этих видах топлива ванадий входит в состав очень устойчивых порфириновых и непорфириновых соединений, а при их сгорании в окружающую среду выделяется в виде оксидов. В процессе сжигания топлива ванадий выделяется в виде твердых частиц вместе с летучей золой (Crans et al., 1998; Mamane, Pirrone, 1998; Nriagu, Pirrone, 1998). В земной коре концентрация ванадия составляет около 0,01\%. В почвах Молдовы в зависимости от состава его содержание колеблется в пределах $10-10^{7}$ мг/кг (Кирилюк, 2006). 
Ванадий - это один из наименее изученных микроэлементов водных экосистем. Поверхностные незагрязненные пресные воды в своем большинстве содержат менее 2 мкг/л ванадия (Zubcova et al., 1998). Ванадий относится к так называемым сателлитам теплоэлектростанций, так как является составной частью твердого и жидкого топлива (Nriagu, Pirrone, 1998). В этой связи настоящая работа нацелена на систематизацию многолетнего материала, оценку процессов миграции ванадия и уровня его накопления в техногеннопреобразованной водной экосистеме - Кучурганском водоеме-охладителе Молдавской ГРЭС.

\section{Материалы и методы}

Кучурганский водоем-охладитель Молдавской ГРЭС расположен в юго-восточной части Молдовы в низовье Днестра в устьевой части речки Кучурган $\left(46^{0} 35^{\prime}-46^{0} 45^{\prime}\right.$ с.ш., $29^{0} 58^{\prime}-29^{0} 59^{\prime}$ в.д.). Средняя глубина водоема составляет 3,5 м, длина - 14-20 км, ширина до 3 км, площадь около 27 км², объем воды 82 млн м³. Де-факто - это остаток залива некогда большого Приднестровского лимана. В 1964 г. была сооружена Молдавская ГРЭС и плотина с регулирующим шлюзом и комплексом гидротехнических сооружений, отделивших лиман от протока Турунчук (рукав реки Днестр). Таким образом, сегодня водный баланс водоема составляют периодически закачиваемые воды Турунчука и высокоминерализованные воды речки Кучурган.

Кучурганский водоем-охладитель - это техногенно-преобразованная эвтрофированная водная экосистема, подверженная термофикации и загрязнению выбросами станции. Минерализация воды достигает сегодня 4000 мг/л, в илах протекают процессы сульфатредукции с выделением сероводорода, отмечены заморные явления, а уровень ор- ганических веществ в воде соответствует 4-5 классу качества - загрязненная-грязная (Zubcov et al., 2016a). Дно водоема покрыто в основном черными и серыми илами, местами с примесью ракушечника, песка или детрита. Песчаные места наблюдаются лишь в нижнем участке.

Водоем подвержен интенсивному зарастанию высшими водными растениями Phragmites australis (Cav.), Typha latifolia L., Potamogeton crispus L., Potamogeton pectinatus L., Potamogeton perfoliatus L., Myriophyllum spicatum L., Salvinia natans L., Ceratophyllum demersum L., Hydrocharis morsus-ranae L., Vallisneria spiralis L., Butomus umbellatus L., Lemna minor L., Lemna trisulca L., Najas marina L. и др. (Zubcov et al., 2016b). Донная малакофауна водоема представлена в основном дрейссеной (Dreissena polymorpha Pallas), а также Lithoglyphus naticoides C. Pfeiffer, Theodoxus fluviatilis Linnaeus, Viviparus contectus Millet, Valvata piscinalis Müller и реликтовым моллюском Hypanis pontica Eichwald.

Образцы воды, биологического материала, илов отбирались по трем участкам Кучурганского водоема-охладителя из водоподводящих и отводящих каналов станции, из речки Кучурган в зоне впадения и из протока Турунчук. Исследовали содержание ванадия и в атмосферных осадках.

Пробы воды отбирались ежемесячно в период 1981-1990 гг., посезонно - в 1991-1995 гг., затем в связи с приватизацией станции и приднестровскими событиями 1996-2007 гг. сбор проб практически прекратился (2-3 пробы в год), а с 2008 г. сбор проводился посезонно (весной, летом, осенью и не всегда зимой) на трех участках. Пробы отбирались в полиэтиленовые банки в соответствии со стандартами, адаптированными на национальном уровне (ISO 5667-3:2012). Непосредственно на месте отбора, реже в течение первых су- 
ток, пробы воды фильтровались через мембранные фильтры с диаметром пор 0,45 мкм и затем подвергались дальнейшей обработке в лаборатории.

Донные отложения отбирали бентометром Гурвича-Цееба, в который для исключения контакта пробы с его металлическими частями вставлялась специальная трубка из плексигласа (Guidance on chemical monitoring..., 2010; ISO 5667-12:1995). Для получения жидкой фазы илов (иловых растворов) пробы донных отложений (2-3 кг) центрифугировали в течение 30-40 мин при 2500-3000 об/мин. В илах также определяли количество общего органического вещества, подвижные формы и количество поверхностно-сорбированного ванадия, а также гранулометрический состав. Методы детально описаны нами ранее (Зубкова, 1996).

Пробы воды и иловых растворов после фильтрации через мембранные фильтры (0,45 мкм) подкисляли азотной кислотой (0,5 мл концентрированной азотной кислоты на 50 мл пробы) и упаривали до 10 мл в термоблоке Hot Block SC 154 Environmental Express (Великобритания) (EN ISO 15587-2:2012).

Непосредственно у станции и вне ее зоны были отобраны образцы атмосферных осадков, в том числе свежий и лежалый (7-8 дней) снег с определенной площади (по несколько квадратов), что позволило рассчитать и количество металла в мкг/ $\mathrm{M}^{2}$, а не только в мкг/л раствора.

Собранные образцы водных растений, гидробионтов промывались природной водой, ополаскивались дистиллированной водой, подсушивались на фильтровальной бумаге, взвешивались. В моллюсках исследовали уровень накопления ванадия в мягких тканях, в раковинах и в целых особях разновозрастных групп. Уровень металла в рыбе определяли в мышцах туловища (полоска мышц в 2-3 см, снятая за передним плавником от брюшка до спины, очищенных от костей и кожи), коже (отделенной от мышц), печени, гонадах, жабрах.

Биологический материал и илы высушивались до постоянного веса в термостате при температуре не выше $80{ }^{\circ} \mathrm{C}$. Высушенные образцы измельчались до состояния пудры с использованием мельницы с агатовой ступкой Homogenizer Fritch Mortar Grinder Pulvirisette-2 (Германия).

Определенная навеска пробы от 50 до 100 мкг подвергалась классической «мокрой» кислотной минерализации. С 90-х гг., использовали метод микроволнового разложения с применением комплекса Speed Wave four SW-4, (Германия), который позволяет сократить время подготовки пробы за счет высоких температур и давления реакционной смеси (азотная кислота для мягких тканей биологических проб и смеси азотной и соляной кислот для илов и раковин моллюсков), получаемых в поле микроволнового излучения, до 15-45 мин для блока из 12 образцов. Кроме того, герметичность тефлоновых автоклавов дает возможность убрать испарение и минимизировать потери летучих компонентов, неизбежных в случае классического кислотного разложения, что практически исключает «человеческий фактор» (Method 3051A, SW-846, 2013). Данное оборудование снабжено программой, которая в каждом конкретном случае указывает количество и соотношение кислот, но их общий объем должен быть не менее 5 мл. Полученный раствор количественно переносится в посуду для последующего анализа на приборе и либо упаривается, либо разбавляется и доводится деионизированной водой до 10 мл.

Образцы анализировали атомноабсорбционным методом (ISO 15586:2003) с 
использованием спектрометра AAnalyst 400 (Perkin Elmer, США), оснащеного автоматизированной системой дозированного введения раствора в атомизатор и регулирования температур с применением электротермического атомизатора, а в последние годы атомно-эмиссионным спектрометрическим методом с индуктивно-связанной плазмой (ISO 11885:2007) с помощью спектрометра Thermo Scientific iCAP 6200 Duo Thermo Fisher Scientific (Великобритания). Этот метод отличается высокой стабильностью, низким уровнем шумов и малой величиной фонового сигнала и позволяет определять в одной пробе большинство металлов, при этом матричные эффекты, а также мешающие влияния со стороны материалов атомизатора практически отсутствуют. Внутренним стандартом служил скандий.

Полученные данные были подвергнуты математической обработке по общепринятым в статистике методам с применением компьютерных программ Microsoft Excel и Statistica.

\section{Результаты и обсуждение}

Динамика ванадия в воде

В Кучурганском водоеме-охладителе динамика содержания ванадия находится в тесной связи с количеством сжигаемого топлива, что особенно четко видно при анализе многолетней динамики. Самые высокие концентрации ванадия (до 28 мкг/л) были установлены в 1985-1988 гг., когда станция имела самую высокую мощность, а основным топливом были уголь и мазут (Zubcova et al., 1998). В эти годы в дождевой воде в зоне станции уровень ванадия достигал 24 мкг/л, а в лежалом снеге - до 1400 мкг/м². В 1991-1995 гг. уровень ванадия опустился до 5-8 мкг/л, а к 2001 г. его содержание уменьшилось до 2,4-4,8 мкг/л. С 2008 г. прослеживается четкая тенденция к увеличению концентрации ванадия с заметным понижением в 2014 г., что было обусловлено количеством сожженного угля и мазута, а также мощностью станции в этот период (рис. 1). Следует также отметить, что в воде протока Турунчук и речки Кучурган концентрации ванадия весь период не превышали 2,4 мкг/л.

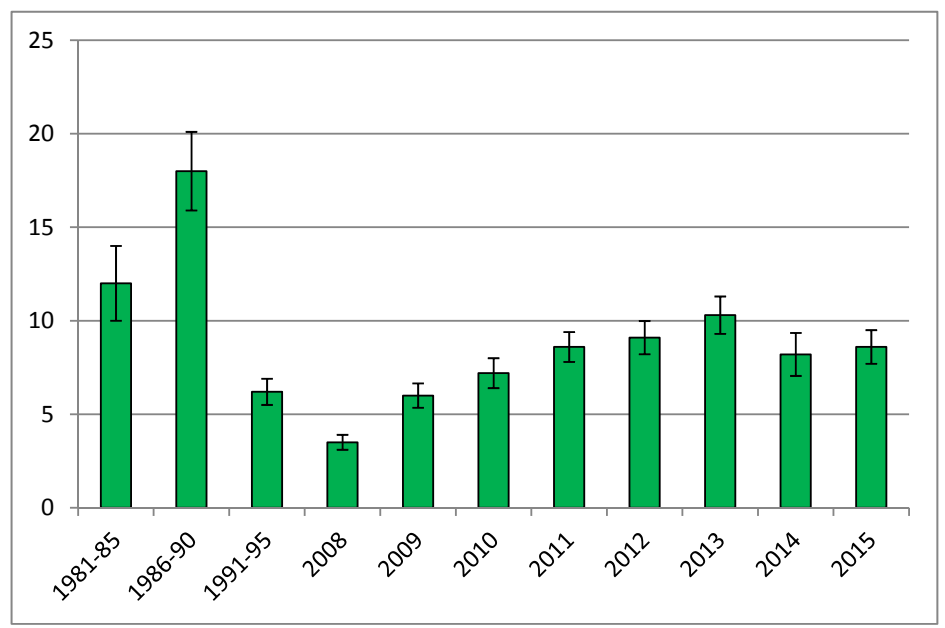

Рис. 1. Динамика среднегодовых величин концентрации ванадия (мкг/л) в воде Кучурганского водоемаохладителя в 1981-1995 и 2008-2015 гг.

Fig. 1. Dynamics of mean annual values of vanadium concentration $(\mu \mathrm{g} / \mathrm{l})$ in water of Kuchurgan cooling reservoir in 1981-1995 and 2008-2015 
В сезонном аспекте повышенные концентрации ванадия отмечены в летне-осенний период; по акватории водоема минимальные величины характерны для нижнего участка, а максимальные - для среднего и верхнего участков (рис. 2), где влияние выбросов станции и термофикация максимальны.

\section{Ванадий в иловых отложениях}

Донные отложения - это самые стабильные компоненты водных экосистем, при исследовании которых можно проследить многолетнюю динамику металлов в водоемах. Донные отложения Кучурганского водохранилища относятся к глинистым илам, при этом мелкодисперсные илы характерны для верхнего участка. Динамика ванадия в донных отложениях зависит от целого комплекса природных условий, воздействия выбросов и в целом функционирования теплоэлектростанции. Уровень концентрирования ванадия непосредственно в донных отложениях во многом определяется физико-химическими особенностями самих илов и, в первую очередь, их гранулометри- ческим составом, количеством органических веществ в них, а также интенсивностью процессов осаждения и адсорбции.

Валовая концентрация ванадия в иловых отложениях верхнего участка водоема в 20112015 гг. варьировала в диапазоне 180-201 мкг/г сух. массы, среднего участка - 139-155 мкг/г сух. массы и нижнего участка - 130-190 мкг/г сух. массы.

В илах Кучурганского водоемаохладителя уровень органических веществ составляет 3,2-5,8 \%. Между валовым содержанием ванадия в илах и количеством в них органических веществ прослеживается положительная корреляция (r $>0,75)$. В то же время между суммой подвижных форм ванадия и количеством органических веществ в илах установлена отрицательная корреляция $(\mathrm{r}<-0,80)$, т. е. подвижность ванадия с увеличением количества органических веществ в илах уменьшается. Несмотря на термофикацию водоема-охладителя и загрязнение его выбросами теплоэлектростанции, валовое содержание ванадия в иловых отложениях

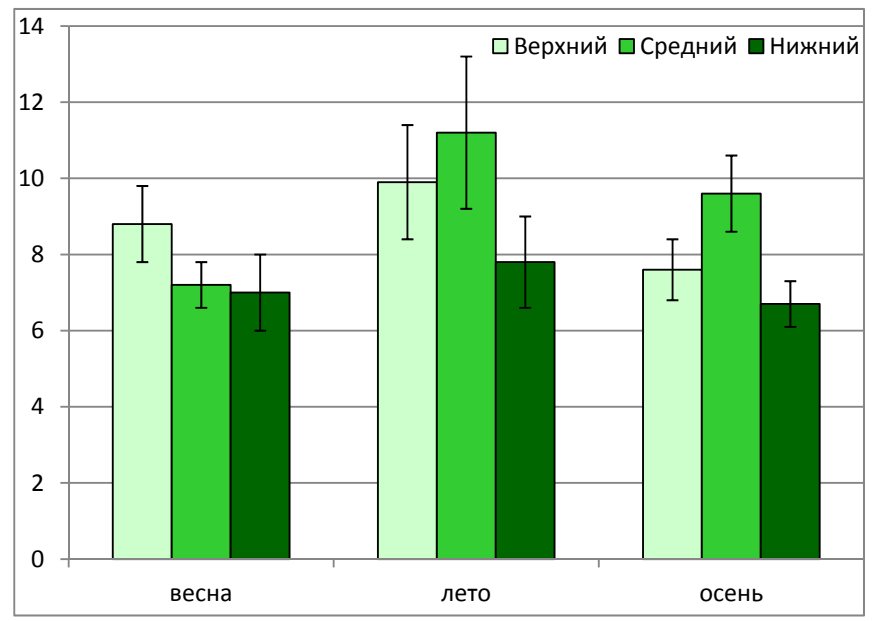

Рис. 2. Сезонная динамика величин концентрации ванадия (мкг/л) в воде Кучурганского водоемаохладителя по участкам в 2012-2013 гг.

Fig. 2. Seasonal dynamics of vanadium concentration $(\mu \mathrm{g} / 1)$ in water of different sectors of Kuchurgan cooling reservoir in 2012-2013 
$\left(\mathrm{V}, \mathrm{n} \times 10^{-4}, \%\right)$ находится в функциональной зависимости от количества пелитовых мелкодисперсных фракций (Р, \%) и концентрации органического вещества $(\mathrm{C}, \%)$, описываемой уравнением

$$
\mathrm{V}=0,12 \times \mathrm{P}+13,7 \times \mathrm{C}+75,6, \quad \mathrm{R}=0,97
$$

Распределение ванадия по гранулометрическим фракциям илов показывает, что его основная масса сконцентрирована в пелитовых мелкодисперсных фракциях с диаметром частиц от менее 0,001 до 0,005 мкм, при этом концентрации ванадия в илах уменьшаются от верхнего к нижнему участку (рис. 3).

Мы исследовали также количество поверхностно-сорбированного ванадия в илах водохранилища. Оказалось, что максимальные количества его обнаружены в илах с меньшим количеством пелитовых фракций и органических веществ нижнего участка Кучурганского водохранилища $(6,8-8,7 \%$ от валового количества) и минимальные - в верхнем участке $-4,2-5,4 \%$.
Уровень ванадия в илах водоема выше, чем в почвах региона (Кирилюк, 2006); это подтверждает аккумулирующую роль илов по отношению к ванадию, а также факт превалирования миграции ванадия в направлении сверху-вниз, из воды в донные отложения. Но в отдельных случаях (при преобладании восстановительных процессов над окислительными, неблагоприятном газовом режиме) илы Кучурганского водохранилища могут служить источником вторичного загрязнения водной толщи соединениями ванадия.

Наиболее динамичной частью донных отложений является иловый раствор. Концентрации ванадия в иловых растворах нижнего и среднего участков водоема-охладителя оказались ниже, а в иловых растворах верхнего участка - выше, чем в придонной воде (табл. 1).

\section{Накопление ванадия в гидробионтах}

Уровень накопления металлов в водных растениях и животных имеет особую значимость как для оценки миграции химических

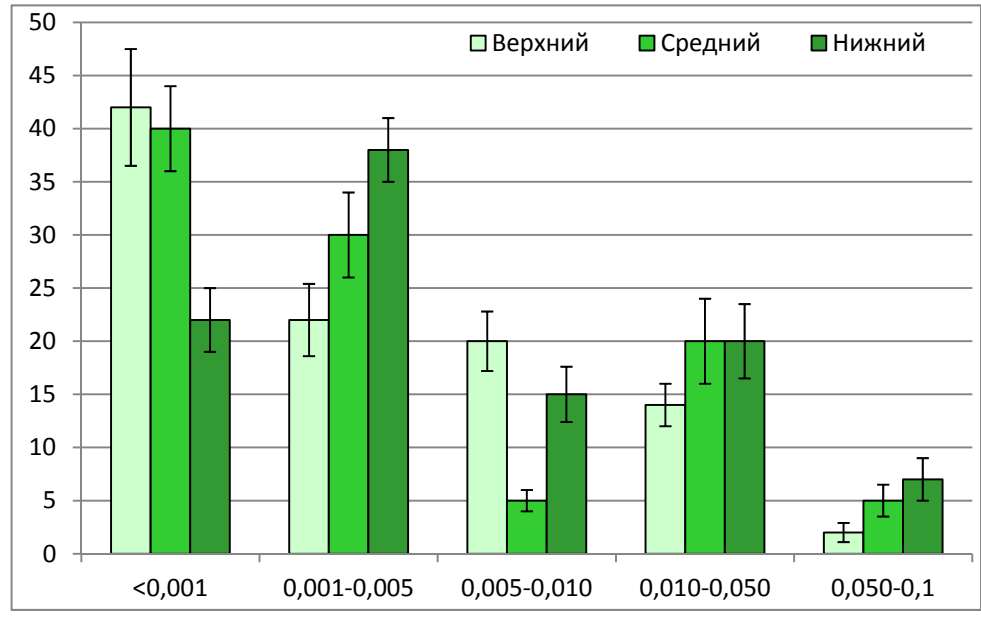

Рис. 3. Содержание ванадия (мкг/г сухой массы) в гранулометрических фракциях илов по участкам Кучурганского водоема-охладителя в 2012-2013 гг.

Fig. 3. Concentration of vanadium ( $\mu \mathrm{g} / \mathrm{g}$ dry mass) in granulometric fractions of silts in different sectors of Kuchurgan cooling reservoir in 2012-2013 
Таблица 1. Концентрации ванадия (мкг/л) в иловых растворах и придонной воде из Кучурганского водоема-охладителя в 2013 г. (средняя \pm стандартная ошибка, $\mathrm{n}=3$ )

Table 1. Concentration of vanadium $(\mu \mathrm{g} / \mathrm{l})$ in silt solutions and bottom waters from Kuchurgan cooling reservoir in $2013($ mean $\pm \mathrm{SE}, \mathrm{n}=3)$

\begin{tabular}{|c|c|c|c|c|c|c|}
\hline \multirow{2}{*}{ Сезон года } & \multicolumn{2}{|c|}{ Верховье } & \multicolumn{2}{c|}{ Середина } & \multicolumn{2}{c|}{ Низовье } \\
\cline { 2 - 7 } & Вода & $\begin{array}{c}\text { Иловый } \\
\text { раствор }\end{array}$ & Вода & $\begin{array}{c}\text { Иловый } \\
\text { раствор }\end{array}$ & Вода & $\begin{array}{c}\text { Иловый } \\
\text { раствор }\end{array}$ \\
\hline Весна & $8,1 \pm 0,8$ & $9,2 \pm 1,1$ & $10,2 \pm 0,7$ & $7,7 \pm 0,7$ & $8,6 \pm 0,8$ & $7,2 \pm 0,7$ \\
\hline Лето & $8,6 \pm 0,7$ & $9,8 \pm 1,0$ & $12,6 \pm 0,9$ & $8,6 \pm 0,8$ & $7,7 \pm 0,8$ & $6,3 \pm 0,9$ \\
\hline Осень & $9,0 \pm 1,0$ & $11,1 \pm 1,2$ & $11,3 \pm 1,0$ & $10,2 \pm 0,9$ & $8,0 \pm 0,9$ & $9,1 \pm 1,0$ \\
\hline
\end{tabular}

веществ в водоемах и водотоках, так и для оценки качества воды. Эти данные позволяют оценить возможные риски, связанные с влиянием загрязнения поверхностных вод на жизнедеятельность не только водных организмов, но и человека. Кроме того, определение уровня загрязненности тяжелыми металлами водных экосистем по их содержанию в гидробионтах является более эффективным, чем прямое определение в воде. Это объясняется тем, что способность гидробионтов концентрировать металлы позволяет получить интегральную оценку среднего содержания элемента за конкретный период времени, в течение которого количество данного металла в воде может очень варьировать (Zubcov et al., 2013b).

В настоящее время наблюдается интенсивное зарастание Кучурганского водохранилища воднылми растениями. Так, в акватории водоема среди макрофитов по всей береговой линии наиболее распространёнными являются тростник (Phragmites australis Cav.), рдест гребенчатый (Potamogeton pectinatus L.) и рдест курчавый (Potamogeton crispus L.), заросли которых периодически покрывают до 80 \% водного зеркала. Видовые особенности растений, химические свойства, биологическое значение микроэлементов, а также их содержание в воде и иловых отложениях обеспечивают довольно широкий диапазон колебаний концентраций металлов в исследованных видах. Уровень накопления металлов в водных растениях определяется как интенсивностью процессов метаболизма растений, так и сезонностью процессов накопления металлов в них (Zubcov et al., 2013a).

Проведенные исследования показали, что в плавающих гидрофитах уровень ванадия чаще выше, нежели в корневищных надводных гелофитах. Содержание ванадия в исследованных водных растениях варьирует в довольно широком диапазоне. Для тростника (Phragmites australis) (стебель с листьями) этот диапазон в пересчете на грамм сухой массы составляет 7,8-13,7 мкг/г, для рогоза широколистного (Typha latifolia L.) 2,7-12,7 мкг/г, сусака зонтичного (Butomus umbellatus L.) - 2,2-10,8 мкг/г, рдеста курчавого (Potamogeton crispus) - 16-39 мкг/г, рдеста пронзеннолистного (Potamogeton perfoliatus L.) - 8,2-12,5 мкг/г, роголистника (Ceratophyllum demersum L.) - 7,2-16,5 мкг/г, водокраса (Hydrocharis morsus-ranae L.) 20,8-42,9 мкг/г, ряски малой (Lemna minor L.) - 20,5-48,2 мкг/г, ряски тройчатой (Lemna trisulca L.) - 19,5-47,2 мкг/г, сальвинии плавающей (Salvinia natans L.) - 27,5-40,4 мкг/г. Указанные для плавающих гидрофитов концентрации ванадия несколько выше наблю- 


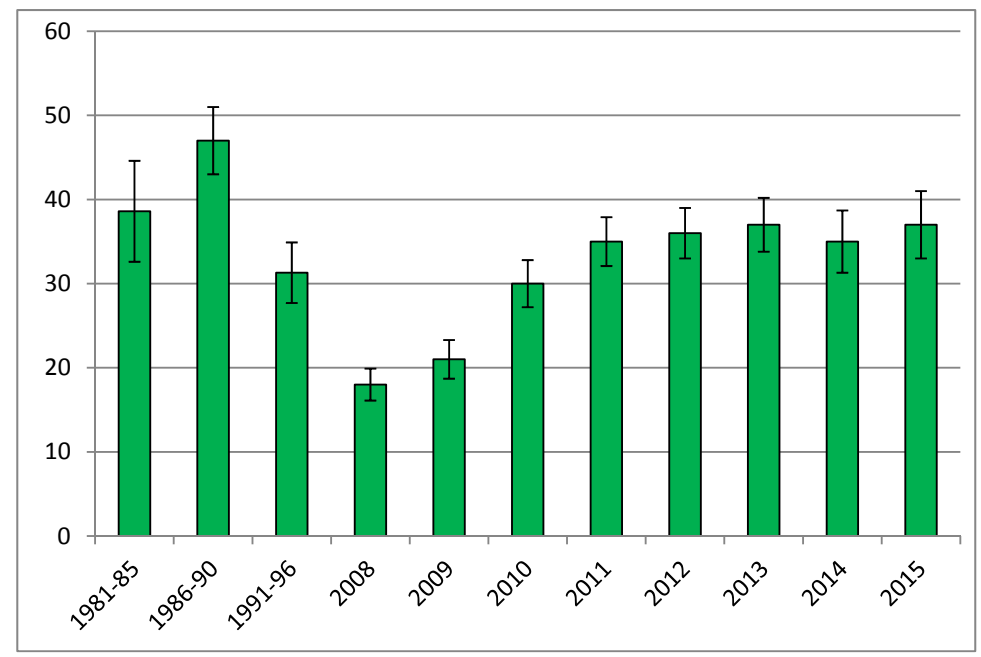

Рис. 4. Многолетняя динамика средних величин концентрации ванадия (мкг/г сухой массы) в плавающей водной растительности (Hydrocharis morsus-ranae L., Lemna trisulca L., Salvinia natans L., Lemna minor L.) из Кучурганского водоема-охладителя в 1981-1996 и 2008-2015 гг.

Fig. 4. Dynamics of mean annual values of vanadium concentration ( $\mu \mathrm{g} / \mathrm{g}$ dry mass) in floating aquatic vegetation (Hydrocharis morsus-ranae L., Lemna trisulca L., Salvinia natans L., Lemna minor L.) from Kuchurgan cooling reservoir in 1981-1996 and 2008-2015

давшихся в 1991-1995 гг., но они ниже тех, что были в 80-е гг. прошлого столетия (рис. 4).

Представителям донных беспозвоночhblx (зообентос) принадлежит особая роль в миграции химических элементов в водоемах и водотоках. Донные беспозвоночные способны образовывать разнообразные экологические связи, они активно перемещаются в пространстве и в отличие от растений более чувствительны к загрязнению тяжелыми металлами (Toderaş et al., 1999). Использование донных беспозвоночных в качестве организмов-индикаторов, аккумулирующих химические элементы, наиболее эффективно, так как они являются конечным или промежуточным звеном трофических цепей. Продолжительность жизненного цикла основной массы макрозообентоса превышает несколько месяцев, поэтому они могут быть использованы в качестве показателей произошедших изменений химического состава воды и донных отложений за определенный промежуток времени. Следовательно, сообщества донных животных - приоритетные индикаторы, по которым можно судить о процессах, происходящих в водоеме, в том числе и о тех, которые вызваны техногенным влиянием (Zubcov et al., 2016b).

Исследована динамика накопления ванадия в массовых видах донных беспозвоночных водоема: из представителей мягкого зообентоса - Chironomidae, Mysidae, из моллюсков - Dreissena polymorpha, Hypanis pontica (Bivalvia) и Viviparus viviparus, Lithoglyphus naticoides (Gastropoda).

В Кучурганском водохранилище особая роль в миграции металлов принадлежит Dreissena polymorpha, фильтрационную способность которой трудно переоценить. Ранее этот моллюск своими колониями (друзы) практически покрывал всю водную растительность и гидросооружения, особенно в зоне водозабора станции. Поэтому с дрейссеновыми колониями постоянно велась борьба. 
С этой же целью водоем зарыбляли черным амуром и другими видами рыб. В последние годы численность моллюска значительно уменьшилась. Стали достаточно редко встречаться крупные особи, а моллюсков с массой тела более 3 г в последние 4 года нам не удалось найти. По всей акватории водоема в последние годы массово наблюдаются мертвые моллюски и практически на всех его участках илы покрыты раковинами дрейссены.

Диапазон колебаний концентраций ванадия в исследованных донных беспозвоночных очень большой. Для Dreissena polymorpha он составляет 3,2-170, для Viviparus viviparus 3,3-57,2, для Lithoglyphus naticoides - 5,5-26,5, для Hypanis pontica - 2,2-42,6, для Mysidae 4,0-8,5, для Chyronomidae 5,1-65,1 мкг/г сухой массы. Такой диапазон обусловлен целым комплексом факторов, в том числе и размерновозрастными параметрами гидробионтов, что необходимо учитывать при мониторинге водных экосистем. Ранее нами была установлена зависимость уровня накопления металлов в донных беспозвоночных от массы их тела (Toderaş et al., 1999). Кроме того, уровень накопления металлов зависит и от параметров среды обитания и от интенсивности процессов метаболизма донных беспозвоночных. Однако в любом случае исследованные нами представители донных беспозвоночных являются мощными биоаккумуляторами ванадия, коэффициент биологического накопления (рассчитанный по отношению концентрации в организме в мкг/г к концентрации в воде в мкг/мл) в них достигает величин в $10^{5}-10^{6}$. Dreissena polymorpha принадлежит первое место среди исследованных нами моллюсков по величине концентрации ванадия как в мягких тканях, так и в пересчете на сухую массу всего тела.

О различии уровня накопления металлов в зависимости от условий водоема по диапазону колебаний судить довольно трудно. Для анализов из Кучурганского водоема нами были отобраны равноразмерные особи моллюска Dreissena polymorpha, собранные в вегетационный период, по которым были рассчитаны среднегодовые величины концентраций в них ванадия (рис. 5). В 1981-1995 гг. отбирали по 5-6 разновозрастных групп дрейссены весной, летом, осенью и определяли уровень металла в пересчете на особь из этих групп. В 2008-2015 гг. мы отбирали по 4-5 групп, так как больших особей с массой тела более 2 г нам собрать не удалось.

Очевидна зависимость уровня накопления ванадия в водных растениях и донных беспозвоночных от динамики металла в воде (рис. 1, 4 и 5).

Значительную роль моллюсков в биогенной миграции химических элементов подтверждает и тот факт, что в их мягких тканях концентрации изучаемых металлов в пересчете как на сырое, так и на сухое вещество выше, чем у других видов донных беспозвоночных. Даже простой расчёт количества включенного в биогенную миграцию ванадия массовыми видами моллюсков в сравнении с мягким зообентосом показывает, что на долю первых приходится более 90 \% от общей массы.

Большой интерес представляют материалы о динамике накопления ванадия в органах и тканях рыб. Нами было исследовано накопление ванадия в мышцах неполовозрелых особей Aristichthys nobilis (Richardson, 1845), Carassius auratus gibelio (Bloch, 1782) и Perca fluviatilis (Linnaeus, 1758). Диапазон колебаний ванадия в пересчете на сухую массу составил в мышцах неполовозрелых особей карася 1,3-3,4 мкг/г, толстолобика - 3,2-4,6 мкг/г и окуня - 2,6-3,8 мкг/г. При этом минимальные количества были отмечены весной, максимальные у карася, толстолобика - летом, а у окуня - осенью. Указанные концентра- 


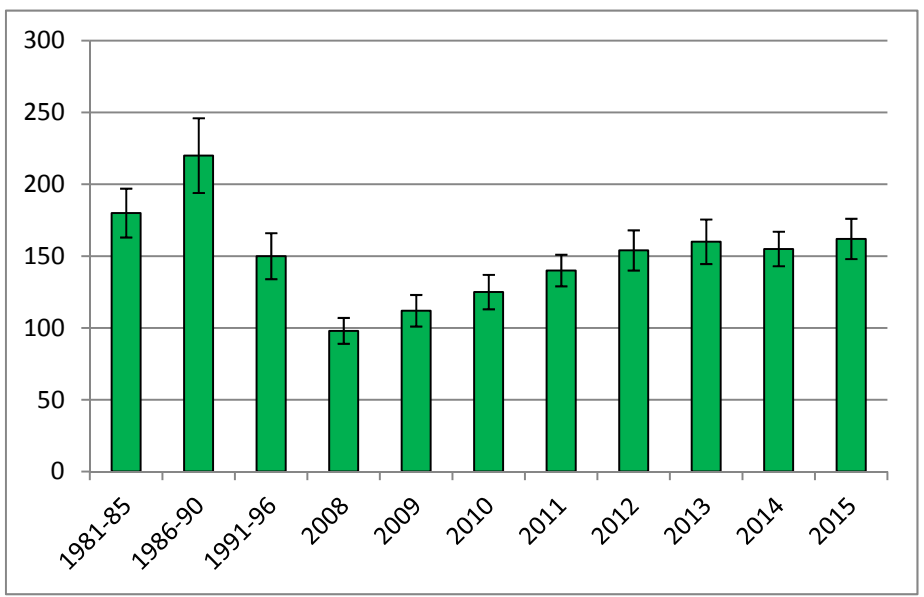

Рис. 5. Динамика среднегодовых концентраций ванадия (мкг/г сухой массы) в Dreissena polymorpha из Кучурганского водоема-охладителя в 1981-1996 и 2008-2015 гг. (n=100 моллюсков с сухим весом 60-300 мг)

Fig. 5. Dynamics of mean annual values of vanadium concentration ( $\mu \mathrm{g} / \mathrm{g}$ dry mass) in Dreissena polymorpha from Kuchurgan cooling reservoir in 1981-1996 and 2008-2015 (n=100 mollusks with a dry weight of $60-300 \mathrm{mg}$ )

Таблица 2. Содержание ванадия (мкг/г сухой массы) в органах и тканях половозрелых особей рыб из Кучурганского водоема-охладителя в 2012-2013 гг. (средняя \pm стандартная ошибка, $\mathrm{n}=12$ )

Table 2. Concentration of vanadium ( $\mu \mathrm{g} / \mathrm{g}$ dry mass) in organs and tissues of sexually matured fish specimens from Kuchurgan cooling reservoir in 2012-2013 (mean $\pm \mathrm{SE}, \mathrm{n}=12$ )

\begin{tabular}{|l|c|c|c|c|c|c|}
\hline \multirow{2}{*}{ Вид рыбы } & \multicolumn{5}{|c|}{ V, мкг/г сух. массы } & \multirow{2}{*}{ Вес рыбы сырой, г } \\
\cline { 1 - 6 } & Мышцы & Гонады & Печень & Жабры & Кожа & \\
\hline $\begin{array}{l}\text { Carassius } \\
\text { auratus gibelio }\end{array}$ & $2,4 \pm 0,8$ & $2,0 \pm 0,6$ & $3,1 \pm 1,0$ & $3,8 \pm 0,8$ & $4,0 \pm 0,5$ & $320 \pm 21$ \\
\cline { 2 - 6 } Perca fluviatilis & $2,8 \pm 0,5$ & $2,2 \pm 0,4$ & $3,4 \pm 0,6$ & $3,6 \pm 0,9$ & $3,9 \pm 0,7$ & $440 \pm 20$ \\
\hline & $2,1 \pm 0,9$ & $1,8 \pm 0,9$ & $2,9 \pm 0,6$ & $2,2 \pm 0,7$ & $3,0 \pm 0,8$ & $380 \pm 18$ \\
\hline $\begin{array}{l}\text { Aristichthys } \\
\text { nobilis }\end{array}$ & $3,3 \pm 0,8$ & $2,4 \pm 1,0$ & $4,0 \pm 0,8$ & $4,2 \pm 1,1$ & $4,1 \pm 1,0$ & $400 \pm 33$ \\
\cline { 2 - 6 } & $3,9 \pm 0,9$ & $1,4 \pm 0,6$ & $5,1 \pm 1,2$ & $6,0 \pm 0,7$ & $4,9 \pm 1,0$ & $2600 \pm 81$ \\
\hline
\end{tabular}

ции ванадия несколько выше, чем данные восьмидесятых-девяностых годов прошлого столетия (Зубкова, 2011).

Анализ ванадия в различных органах половозрелых рыб показал, что уровень его накопления, как правило, ниже в гонадах и мышцах, а максимумы установлены в коже и жабрах (табл. 2), т. е. в органах, непосредственно контактирующих с водной средой обитания. Естественно, что рыбы в большей степени, нежели беспозвоночные животные, регулируют уровень аккумуляции микроэлементов. В то же время влияние среды обитания очевидно. Об этом свидетельствует и то, что содержание такого металла, как ванадий, в органах и тканях рыб Кучурганского водохранилища заметно выше, чем в других водных экосистемах Молдовы (Зубкова, 2011), 
хотя и не превышает установленные ПДК для рыбопродуктов.

\section{Заключение}

Дымовые выбросы Молдавской ГРЭС являются источником загрязнения ванадием водной среды, донных отложений, водной растительности, донных беспозвоночных и рыб, о чем свидетельствует многолетняя динамика металла в экосистеме водоема-охладителя. Исследования процессов накопления металлов в иловых отложениях и гидробионтах техногенно-преобразованных водных экосистем должны быть составляющими в программах комплексного мониторинга миграции металлов и гидробиологического контроля загрязнения водных экосистем, а также необходимы для оценки буферной емкости водных экосистем и для разработки современных программ устойчивого их менеджмента.
Кучурганский водоем на современном этапе - это трансграничный водный объект, и в соответствии с Директивами ЕС по воде его экологическое состояние зависит от природоохранных мер, проводимых обеими странами, причем эти меры должны опираться на результаты постоянного научнообоснованного комплексного экологического мониторинга. Устойчивое использование водоема должно быть направлено на кардинальное улучшение его эксплуатации, уменьшение опасных дымовых выбросов, проведение своевременной «продувки водоема», удаление высшей водной растительности и зарыбление.

\section{Благодарности}

Часть материала получена в рамках реализации молдово-украинского двустороннего проекта 14.820.18.02.01/U и Институционного проекта 15.817.02.27A- AQUASYS.

\section{Список литературы}

Зубкова Е.И. (1996) Тяжелые металлы в донных отложениях Днестра и Дубоссарского водохранилища. Гидробиологическийжурнал, 4: 94-102 [Zubcova E.I. (1996) Heavy metals in the bottom sediments of the Dniester and Dubossary reservoir. Hydrobiological Journal [Gidrobiologicheskij zhurnal], 4: 94-102 (in Russian)]

Зубкова Н. (2011) Закономерности накопления и роль микроэлементов в онтогенезе рыб. Chisinau, Ştiinţa, 88 c. [Zubcova N. (2011) Regularities of the accumulation and the role of trace elements in fish ontogenesis. Chisinau, Ştiinţa, 88 p. (in Russian)]

Кирилюк В.П. (2006) Микроэлементы в компонентах биосферы Молдовы. Chisinau, Pontos, 155 c. [Kiriliuk V.P. (2006) Trace elements in the biosphere components of Moldova. Chisinau, Pontos, 155 p. (in Russian)]

Asadpour Y.A., Nejatkhah Manavi P., Baniamam M. (2013) Evaluating the bioaccumulation of nickel and vanadium and their effects on the growth of Artemia urmiana and A. franciscana. Iranian Journal of Fisheries Sciences, 12(1): 183-192

Crans D., Amin S., Keramidas A. (1998) Chemistry of relevance to vanadium in the environment. Vanadium in the environment. Part 1: Chemistry and biochemistry. Nriagu J. (ed.) New York, NY, John Wiley \& Sons, p. 73-96

EN ISO 15587-2:2012 (National version: SM SR EN ISO 15587-2:2012) (2012) Water quality: Digestion for the determination of selected elements in water. Part 2: Nitric acid digestion. $17 \mathrm{p}$.

Guidance on chemical monitoring of sediment and biota under the Water Framework Directive (2010) Luxembourg, Office for Official Publications of the European Communities, $82 \mathrm{p}$.

$$
-457-
$$


ISO 11885:2007 (National version: SM SR EN ISO 11885:2012) (2012) Determination of selected elements by inductively coupled plasma optical emission spectrometry (ICP-OES). $28 \mathrm{p}$.

ISO 15586:2003 (National version: SM SR ENISO 15586:2011) (2011) Water quality: Determination of trace elements using atomic absorption spectrometry with graphite furnace. $23 \mathrm{p}$.

ISO 5667-3:2012 (National version: SM SR EN ISO 5667-3:2011) (2012) Water quality: Sampling. Part 3: Guidance on the preservation and handling of water samples. $42 \mathrm{p}$.

ISO 5667-12:1995 (National version: SM SR ISO 5667-12:2007) (2007) Water quality: Sampling. Part 12: Guidance on sampling of bottom sediments. $51 \mathrm{p}$.

Mamane Y., Pirrone N. (1998) Vanadium in the atmosphere. Vanadium in the environment. Part 1: Chemistry and biochemistry. Nriagu J. (ed.) New York, NY, John Wiley \& Sons, p. 37-71

Method 3051A, SW-846 (2013) Microwave assisted acid digestion of sediments, sludges, soils and oils. US Environmental Protection Agency, 30 p.

Nriagu J., Pirrone N. (1998) Emission of vanadium into the atmosphere. Vanadium in the environment. Part 1: Chemistry and biochemistry. Nriagu J. (ed.) New York, NY, John Wiley \& Sons, p. $25-36$

Proctor D.M., Shay E.C., Fehling K.A., Finley B.L. (2002) Assessment of human health and ecological risks posed by the uses of steel-industry slags in the environment. Human and Ecological Risk Assessment, 8: 681-711

Report WHO (2001) Concise International Chemical Assessment Document 29 Vanadium pentoxide and other inorganic vanadium compounds. $54 \mathrm{p}$.

Toderaş I., Zubcov E., Bileţchi L., Zubcov N. (1999) Rolul funcţional al populaţiilir nevertebratelor bentonice în migraţia biogenă a microelementelor. Anale şstiinţifice ale Universităţii de Stat din Moldova. Chisinau, p. 137-140 [Toderash I., Zubcov E., Biletchi L., Zubcov N. (1999) Benthic invertebrate populations functional role in the biogenic migration of microelements. Scientific Annals of the State University of Moldova. Chisinau, p. 137-140 (in Romanian)]

Zubcova E., Toderash I., Ichim M. (1998) Dynamics of vanadium in the Cuciurgan cooling reservoir. TIEES-98. Trabzon, Turkey, p. 138-140

Zubcov E., Biletchi L., Philipenko E., Ungureanu L. (2013a) Study on metal accumulation in aquatic plants of Cuciurgan cooling reservoir. Proceedings of the $16^{\text {th }}$ International Conference on Heavy Metals in the Environment, Rome, Italy. DOI:10.1051/e3sconf/20130129008

Zubcov E., Biletchi L., Zubcov N., Philipenko E., Borodin N. (2013b) The metal accumulation in aquatic plants of Dubăsari and Cuciurgan reservoirs. Muzeul Olteniei Studii şi comunicări. Ştiinţele Naturii, 2, Tom. 29, p. 216-219

Zubcov E., Tihonenkova L., Biletchi L., Borodin N. (2016a) Dynamics of nutrients in the ecosystem of Cuciurgan cooling reservoir of the Moldovan power plant. Annals of "Dunarea de jos" University of Galati. Mathematics, physics, theoretical mechanics fascicle ii, year VIII (XXXIX), nr. 2. p. 151-157

Zubcov E., Toderas I., Zubcov N., Bilețchi L. (2016b) Cap. IV Repartizarea, migrația și rolul microelementelor în apele de suprafață. Microelementele în componentele biosferei și aplicarea lor în agricultură și medicină. Monografie colectivă. Toma S. (ed.) Pontos, p. 78-107 [Zubcov E., Toderash I., Zubcov N., Biletchi L. (2016) Distribution, migration and the role of trace elements in surface waters. Trace elements in the biosphere components and their application in agriculture and medicine. Toma S. (ed.) Pontos, p. 78-107 (in Romanian)] 